\title{
TIPO/RETÓRICA
}

\section{Una aproximación a la Retórica Tipográfica}

\section{Roberto Gamonal Arroyo (robertogamonalyahoo.es}

Profesor de Diseño Gráfico y Análisis de la Imagen. Universidad Francisco de Vitoria.

\section{Resumen}

A simple vista la Retórica y la Tipografía parecen dos disciplinas con poco en común, pero en este artículo veremos cómo estas dos materias, con muchos siglos de existencia, tienen nexos inquebrantables que abren nuevas vías de investigación. La letra es la representación verbal y visual de nuestro lenguaje y nuestro pensamiento. Su agrupación en palabras y oraciones conforman textos cuyo objetivo principal es persuadir al lector para ser leídas. Y esta persuasión la ejerce no sólo a través de su contenido, sino también de su forma.

\section{Palabras clave}

Retórica - Tipografía - Retórica Visual - Retórica Tipográfica - Persuasión - Diseño Gráfico

\section{Abstract}

At first Rhetoric and Typography seem two disciplines with little in common, but in this article we will see how these two matters, with many centuries of existence, have unshakeable nexuses that open new routes of investigation. The letter is the verbal and visual representation of our language and our thought. Their grouping in words and phrases conforms texts whose primary target is to persuade the reader to be read. And this persuasion exerts it not only through its content, but also of its form. 


\section{Key words}

Rhetoric - Typography - Visual Rhetoric - Typographic Rhetoric - Persuasion - Graphic Design

Pero,/ tipografía,/ déjame/ celebrarte/ en la pureza/ de tus/ puros perfiles,/ en la redoma/ de la letra/ O,/ en el fresco/florero/ de la/ Y/ griega,/ en la/ Q/ de Quevedo,/ (¿cómo puedo pasar/ mi poesía/ frente a esa letra/ sin sentir el antiguo escalofrío/ del sabio moribundo?),/ a la azucena/ multiplicada/ de la/ E/ escalonada para subir al cielo,/ en la Z/ con su rostro de rayo,/ en la P/ anaranjada.

Amor,/ amo/ las letras/ de tu pelo,/ la/ U/ de tu mirada,/ las S/ de tu talle.

En las hojas/ de la joven primavera/ relumbra el alfabeto/ diamantino,/ las esmeraldas/ escriben tu nombre/ con iniciales frescas de rocío.

Mi amor,/ tu cabellera/ profunda/ como selva o diccionario/ me cubre/ con su totalidad/ de idioma/ rojo.

Fragmento de Oda a la Tipografía de Pablo Neruda (1956)

\section{Una aproximación entre Retórica y Tipografía}

La Retórica Clásica, desde sus orígenes allá por el siglo V a.C., se ha encargado de sistematizar el estudio del discurso oral como instrumento persuasivo en los foros jurídicos y políticos. Los clásicos establecieron las cinco fases de creación del discurso: inventio, dispositio, elocutio, memoria y actio. Aristóteles introdujo como base de su Retórica el argumento, personificado en la figura del entimema, razonamiento elaborado mediante premisas probables (Aristóteles, 1990, 19).

Pero con el paso de los años la argumentación dejó de ser la piedra angular sobre la que se construía el discurso y la disciplina quedó reducida a un mero catálogo de figuras retóricas. Esto ha supuesto para la Retórica un gran lastre que impidió su desarrollo y generó una connotación peyorativa en torno a ella de lenguaje ampuloso y rebuscado. Este descrédito se debe a un excesivo ensalzamiento de la elocutio frente a las otras fases constituyentes del discurso que son de vital importancia como la inventio y la dispositio. 
Desde hace varias décadas asistimos a un renacimiento de la Retórica, impulsada por la publicación en la década de los 60 del pasado siglo XX del “Tratado de la argumentación: la nueva retórica” de Perelman y Olbrechts-Tyteca. (Mortara Garavelli, 1991, 7). A partir de esta obra, la Retórica despertó de su letargo y extendió sus redes más allá del discurso y del lenguaje. Roland Barthes, su discípulo Jacques Durand y los integrantes del Grupo $\mu$, entre otros, empezaron a sentar la bases de una Retórica Visual, trasladando los conocimientos fraguados durante siglos alrededor del lenguaje y la literatura al terreno de la imagen.

Por su parte, la Tipografía nace con la estandarización de la escritura mediante los tipos móviles y su impresión. A pesar de que su invención se atribuye a Gutenberg en 1440, existen antecedentes que confirman que en China ya se usaban tipos móviles, aunque de madera, en el año 960. Oficialmente, el inventor de los tipos móviles es Pi Sheng que en el 1045 fabricó caracteres de arcilla endurecida al fuego usando moldes de metal.

La Tipografía es la representación gráfica del lenguaje a través de la escritura formalizada y estandarizada. Como disciplina se encarga del estudio y la clasificación de familias o tipos de letras, así como del diseño de esos caracteres y su composición para formar un texto. Pero también es el procedimiento de impresión mediante tipos móviles utilizados en la confección de libros, revistas, periódicos y otros materiales de comunicación escrita.

Tras estas definiciones vislumbramos cómo la Tipografía se encarga, primero, de perfilar las formas de las letras y segundo, de organizarlas en palabras, oraciones, párrafos, en definitiva, textos que sean capaces de cautivar al lector para que sean leídos.

En la primera afirmación subyace la idea de que una letra es también una imagen y en la segunda, subyace la idea de texto. El tipo es imagen y texto a la vez. A Martin Solomon le gustaba llamarlo: TIPO-ICONO-GRAFÍA, una única palabra en la que se unen la letra, la imagen y la escritura. (Solomon, 1988, 8).

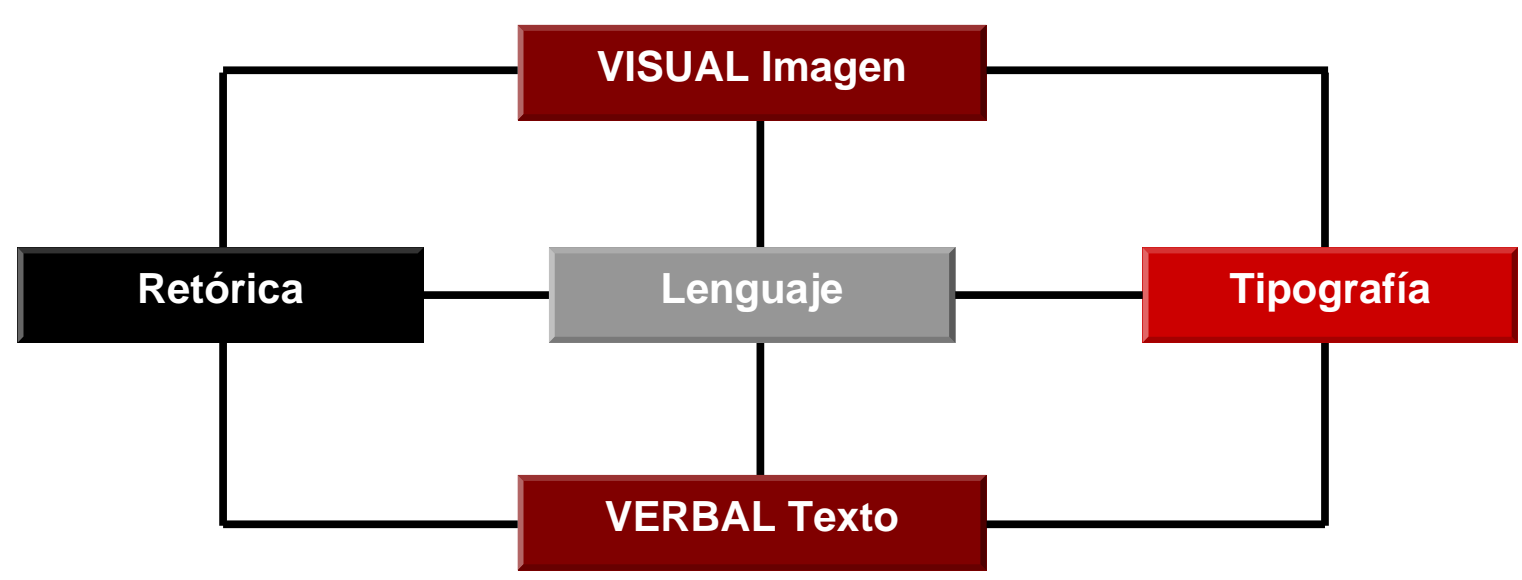


Juan Martínez-Val, en su libro “Tipografía Práctica”, culmina su primer capítulo con unas conclusiones que tienen muy en cuenta la triada "letra-imagen-escritura" haciendo un alegato a favor del respeto a la Tipografía y aproximando esta disciplina a la Retórica (Martínez-Val, 2002, 53):

- Las letras son cosas:

Parafraseando a Frederic W. Goudy que decía que "las letras son cosas, no imágenes de cosas”, el autor afirma que las letras son entidades con personalidad propia que no podemos alterar de manera caprichosa porque son un bien social bello y práctico. Nos recuerda que la escritura se basa en símbolos anclados en la historia y en la sociedad.

- Las letras son imágenes de cosas:

En los albores del nacimiento de la escritura, las letras fueron imágenes de cosas. Aunque esto se ha perdido debido a la abstracción de los signos de los antiguos alfabetos, la letra sigue siendo una imagen. Martínez-Val no está de acuerdo con la famosa cita de “una imagen vale más que mil palabras” porque una palabra impresa ya es, en sí misma, una imagen. Un ejemplo claro es que cuando leemos un texto, instintivamente, no nos fijamos en las formas de las letras. Pero cuando ese texto está escrito en una lengua extranjera que no conocemos, contemplamos las letras como formas, como imagen.

- Las letras son productos históricos:

Cada uno de los diseños de letras que se han realizado a lo largo de la historia viven pegados al tiempo en que nacieron y se desarrollaron. Las letras nos hablan de ese tiempo y reflejan el espíritu de su época y el de los hombres que las crearon.

- Las letras son representaciones fonéticas:

Las letras que forman una palabra nos remiten a imágenes mentales de lo que esas palabras representan en el lenguaje verbal (significante y significado).

- Las letras son símbolos retóricos:

El autor afirma que se trata de una Retórica en el sentido que estamos apuntando en este artículo y que ya los griegos concebían como el conjunto de técnicas que se utilizan para crear un mensaje persuasivo y mejorar su eficacia. No una Retórica ampulosa, vana y vacía. Inevitablemente, cuando imprimimos un texto llenamos la página de sensaciones y emociones asociadas a las letras que usamos. Estas sensaciones, asegura el autor, pueden tener un carácter nacional o una implicación tecnológica e incluso política, religiosa o geográfica. No existe una tipografía neutra. Todas están llenas de simbolismo. Este es el extraordinario poder de la Tipografía: su fuerza simbólica. 
Martínez-Val cierra estas conclusiones con un ejercicio poético y lleno de Retórica: "Hay letras líricas y otras pesadas como elefantes; tipografías femeninas y tipografías masculinas; caracteres que emprenden el vuelo con facilidad y dilatan la fantasía y escrituras que nos pegan a la dura piel de los negocios”.

\section{La Tipografía y las dos Retóricas}

En la Tipografía se dan la mano la Retórica Verbal y la Retórica Visual ya que las letras son a la vez signos lingüísticos y signos visuales. La fuerza simbólica que tiene la Tipografía y que nos señala Martínez-Val no es otra cosa que Retórica, entendida a la manera del Grupo $\mu$ (1987) como un conjunto de operaciones que transforma el sentido estricto del lenguaje (grado cero) en un lenguaje figurado lleno de nuevos y múltiples significados.

Los caracteres pueden transmitir no sólo información textual, sino también múltiples emociones y sensaciones a través de su forma. La elección de un tipo de letra nunca es arbitraria y requiere un ejercicio de reflexión que siempre tiene en su punto de mira al lector-receptor y los conceptos e ideas que se le quieren transmitir.

La expresión puede alterarse con un simple cambio tipográfico. Un mismo texto compuesto con diferentes tipos produce sensaciones diferentes, aunque digan exactamente lo mismo.

Willberg y Forssman (2002) afirman que este efecto se produce por dos motivos:

- la forma abstracta de los caracteres: finos, gruesos, redondos, sinuosos, rudos, elegantes, etc.

- la experiencia vital de una escritura: es decir, por lo que se ha vivido con ella.

Emil Ruder (1983) ahonda en esta cuestión diciendo que la tipografía tiene dos caras: por un lado, está condicionada por su finalidad práctica y por otro, se expresa mediante un lenguaje artístico formal. Tanto forma como función están directamente determinados por la época en las que fueron creadas o fueron utilizadas.

Esta retrospección al carácter temporal de la Tipografía nos remite al concepto retóricoaristotélico de topoi. Aristóteles los concebía como los lugares comunes y específicos a los que acudía el rethor para buscar sus argumentos para elaborar el discurso. Los lugares pueden agruparse 
en lugares de la cantidad, la cualidad, el orden (temporal o espacial), lo existente, la esencia y la persona (Perelman y Olbrechts-Tyteca, 1994:147).

Claros ejemplos de la "experiencia vital” de las letras son estas creaciones tipográficas:

- La tipografía basada en la letras capitales de la columna trajana nos remiten indefectiblemente a la Antigüedad Clásica y los gloriosos tiempos de Roma.

- Los rasgos sinuosos y puramente ornamentales del tipo de letra Art Nouveau nos conducen a finales del siglo XIX y principios del XX donde se desarrolló el movimiento artístico que lleva el mismo nombre.

- La letra gótica es un caso especial en el que se aúnan cuestiones temporales, geográficas y políticas. Se trata de un tipo de escritura desarrollado antes de la invención de la imprenta, pero adaptado a ella en sus comienzos. La letra gótica nos remite temporalmente a la Edad Media, geográficamente a los países centroeuropeos (concretamente a Alemania) y políticamente al nazismo. Aunque la gótica sea un tipo de letra “inocente”, lleva el estigma negativo de haber servido como “tipografía oficial” de la propaganda nazi.

La Tipografía y la Retórica tienen como nexo de unión el Lenguaje. Ambas trabajan con las letras como materia prima, tratándola como texto e imagen a la vez. La Retórica, elaborando textos persuasivos y la Tipografía, dándoles una presencia atractiva que invite a su lectura.

Pero la persuasión, aunque es la función más clásica de la Retórica, no es la única:

- Función comunicativa: la Retórica toma el sentido del lenguaje estricto para transformarlo en un lenguaje figurado, un nuevo mensaje capaz de convencer y persuadir. Toda comunicación lleva implícita la persuasión.

- Función constructiva: mediante la utilización de las figuras retóricas se puede construir un mensaje con una finalidad determinada y dirigido a un público determinado.

- Función estética: la Retórica busca persuadir a través de los argumentos y conmover a través de la belleza del lenguaje. Esta función suele utilizarse en la poesía.

- Función didáctica: la Retórica facilita la comprensión de los textos mediante comparaciones que nos hacen más accesibles las ideas y conceptos (metáforas, símiles...). No en vano la Retórica se impartió en la escuela clásica y medieval como una asignatura esencial. 
La Tipografía también comparte estas funciones con la Retórica:

- Función comunicativa: los signos tipográficos son traducidos del lenguaje escrito al lenguaje hablado y adquieren un significado a través de la lectura. La Tipografía busca la mejor disposición formal de los textos para que éstos comuniquen y sean leídos con claridad. Mediante su legibilidad se asegura su comunicación.

- Función constructiva: la Tipografía se encarga del diseño de las letras. Con los tipos formamos palabras, con las palabras oraciones y con las oraciones textos de muy diferente extensión que se pueden transformar en libros, revistas, periódicos y otros materiales de comunicación escrita.

- Función estética: la forma de las letras tienen como objetivo la legibilidad de los textos, pero esas formas también tienen implícito un componente estético que las hace ser bellas: la sinuosidad de los remates, las sutilezas de las modulaciones...

- Función didáctica: la Tipografía contribuye a la compresión de los textos mediante la legibilidad y su ordenación dentro del espacio de la página en blanco. A través de los tiempos, la cultura se ha transmitido de generación en generación gracias a la plasmación del saber en los libros.

No nos olvidemos de la función persuasiva. También la Tipografía busca persuadir al lector para que lea un texto mediante la elección de un tipo de letra adecuado y una composición clara, atractiva y legible.

\section{Tipo/Retórica: trabajando juntas}

La Retórica ayuda a la Tipografía a explicarse y ser entendida, a facilitar su práctica cotidiana y a su construcción de forma ordenada y sistemática.

Interviene en la Tipografía en dos niveles:

- como texto: la Tipografía ha generado una gran cantidad de textos que la explican como disciplina. Alrededor de ella se ha creado una literatura específica y con ella, se ha desarrollado un lenguaje técnico o jerga que la explica, denominando los elementos que intervienen en ella con vocablos específicos. La Retórica está presente en estos textos en los que aparecen metáforas, comparaciones y otras figuras retóricas 
que ayudan a aquellos que no son expertos en la materia a comprenderla mejor. En este nivel interviene la Retórica tradicional.

- como imagen: ya hemos dicho que la letra o el tipo es una entidad visual y como tal, se rige por la sintaxis del lenguaje visual. El punto, la línea, la masa, el plano, el tono y la textura son los elementos con los que se construye este lenguaje que sigue los principios del Diseño basados en las leyes de la composición visual: relación, transición, repetición, oposición, prioridad, posición, equilibrio, contraste y ritmo (Solomon, 1988, 11). Se produce una traslación del lenguaje verbal al lenguaje visual en el que interviene la Retórica Visual o Retórica de la Imagen.

Fruto de la unión de ambas disciplinas y de su intervención en la letra dentro del nivel textual y visual a la vez, se da la Poesía Visual, un claro exponente de que Retórica y Tipografía pueden trabajar juntos aumentando su poder de expresión. ${ }^{1}$

Esta cualidad poética de la Tipografía se puede potenciar mediante la Retórica. Emil Ruder $(1983,18)$ nos habla de un atributo poético (y a la vez retórico) que está presente en la Tipografía: el ritmo. Dice lo siguiente:

“En los caracteres existe una imagen rítmica donde trazos rectos, curvos, verticales, horizontales y oblicuos se unen y se combinan en una cadencia visual. El texto también contiene valores rítmicos: prolongaciones superiores e inferiores, formas redondas y agudas, simétricas y asimétricas. El espaciado divide las líneas en palabras de longitudes desiguales, en un juego de varios tiempos y valores de diferente densidad. Las líneas quebradas o en blanco añaden sus propios acentos a la composición y la graduación de los cuerpos constituye otro medio excelente de impartir el ritmo a un trabajo tipográfico.”

\subsection{Retórica para comprender la Tipografía}

La Retórica puede hacer que la Tipografía sea más accesible y comprensible para los profanos en la materia y a crear un lenguaje técnico específico para los expertos en ella.

\footnotetext{
${ }^{1}$ Los trabajos de Joan Brossa son un excelente ejemplo de la capacidad poética de la Tipografía. Pueden ver algunos ejemplos en http://www.joanbrossa.org/obra/brossa_obra_poesia_visual.htm
} 


\subsubsection{La transparencia de la Tipografía}

Beatrice Warde creó, a mi juicio, la mejor metáfora jamás construida para explicar qué es la Tipografía y qué función tiene. Con una metáfora se designa un objeto mediante otro que tiene con el primero una relación de semejanza. La autora americana comparó la Tipografía con una fina y transparente copa de cristal. Alrededor de esta figura retórica, elaboró una conferencia magistral titulada "La copa de cristal” que impartió en 1932 a los miembros del gremio de tipógrafos ingleses en el Saint Bride Institute de Londres (McLean, 1995, 73-79).

Warde pone en escena dos copas para servir un vino: una de oro profusamente adornada y otra de vidrio delgado y transparente. ¿Cuál elegiría un buen conocedor y degustador de vino? La segunda, porque le permitirá apreciar todas las cualidades del caldo y apreciarlo con los cinco sentidos. Con la primera se verá limitado el sentido de la vista y no podrá apreciar el vino en toda su extensión.

A juicio de la autora, trasladando esta comparación al mundo de la Tipografía, el diseñador y el tipógrafo deberían hacer la misma elección y optar por la transparencia y la legibilidad de la tipografía, huyendo de adornos superfluos y tipos de letra recargados que dificultan la lectura: “En ella (la copa de cristal) tienes el largo tallo que evita que la huella de tus dedos marquen la copa. ¿Por qué? Porque nada debe nublar tu vista del fogoso corazón del líquido. ¿No tienen la misma utilidad los márgenes de la página de un libro que evitan que tapes con tus dedos la caja del texto?” Warde continúa comparando las partes de la copa con las partes de un libro: “Cuando una copa tiene una base pequeña por muy correcto que sea su peso tú estás preocupado ante la posibilidad de que vuelque; así hay formas de colocar líneas de texto que, aunque en general trabajen bien, el lector estará preocupado inconscientemente por la posibilidad de "saltarse” una línea o leer tres palabras como si fueran una sola y su lectura no será placentera.”

Pero ésta no es la única figura retórica que utiliza Beatrice Warde en su disertación. También la compara con una casa con múltiples ventanas: "El tipógrafo de libros tiene ante sí el trabajo de erigir una ventana entre el lector, que se encuentra dentro de la habitación, y el paisaje que son las palabras del autor. Y la puede hacer de un cristal tallado, de hermosa belleza pero de poca utilidad como ventana; esto es, puede utilizar un magnífico tipo gótico que queda muy bien para ser visto, pero no para ver a través del mismo. O puede utilizar lo que yo llamo tipografía transparente o invisible”.

La conclusión de la autora es que las palabras son formas de transferencia del pensamiento y la Imprenta tiene como misión universal la transmisión de conocimientos, ideas e imágenes de unas 
mentes a otras. Ante esta gran responsabilidad, propone el uso del tipo “invisible” que no distraiga la atención del lector en aspectos banales y le ayuda a centrarse en la lectura.

\subsubsection{La anatomía del tipo y del carácter}

Si en el anterior apartado veíamos que la figura retórica empleada para explicar la Tipografía era la metáfora, ahora vamos a ver cómo el tropo de personificación o prosopopeya nos ayuda a entender las partes en las que se compone la letra. Esta figura consiste en la atribución de cualidades humanas a animales, vegetales, seres inanimados o entidades abstractas. Este tropo, generalmente utilizado en la Literatura, puede ser trasladado perfectamente al plano visual.

En la época de la impresión en plomo, el tipo es un objeto tridimensional, un bloque metálico con forma de paralepípedo que se emplea para la composición de moldes tipográficos y que tiene grabado en una de sus caras un letra o un signo en relieve y al revés. El carácter es el reflejo del tipo impreso en un espejo de papel.

Esta materialidad del tipo hizo que las partes en las que está compuesto fueran denominadas con nombres relacionados con campos semánticos relativos al Hombre y la Naturaleza. Los propios tipógrafos utilizaron vocablos ya usados basándose en similitudes formales o funcionales y añadiéndoles un nuevo significado. Palabras como cuerpo, hombro, pie u ojo adquieren nuevas acepciones dentro de la Tipografía. (Martín, E., 1970, p.136).
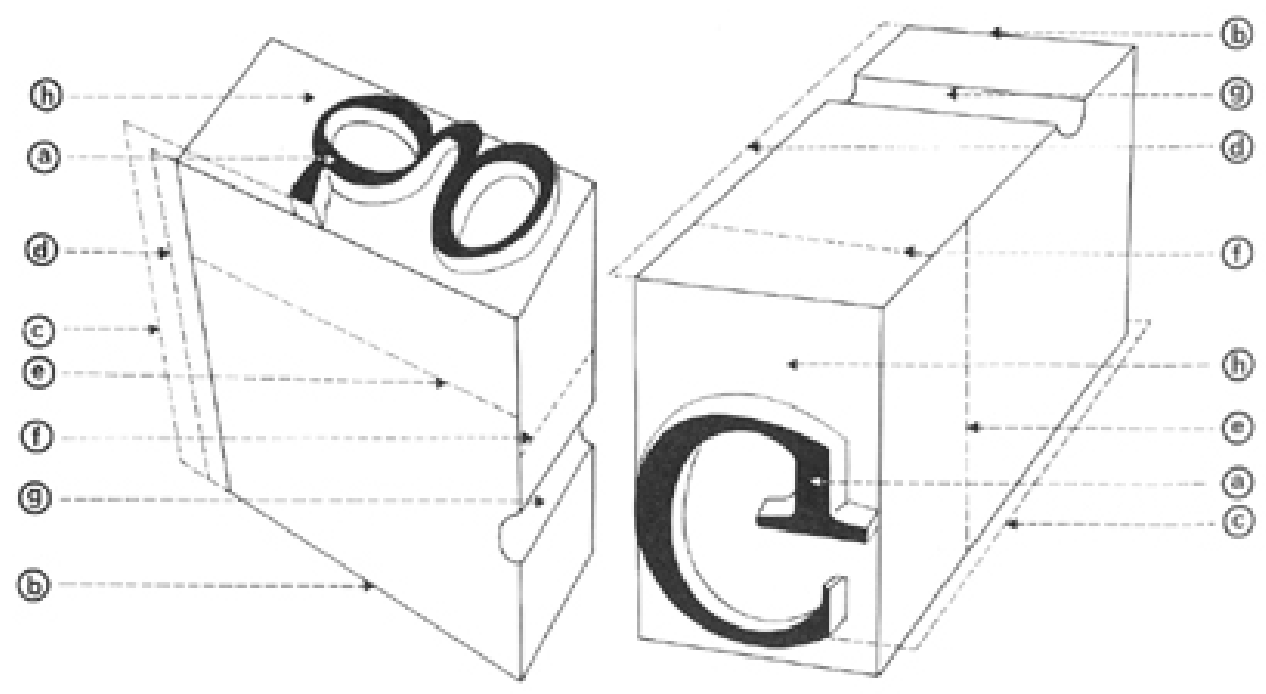

a) ojo b) pie c) altura d) árbol e) cuerpo f) espesor o grueso g) cran o estría h) hombro 
Con la llegada de la fotocomposición y los ordenadores, los tipos móviles empiezan a desaparecer y con ellos su materialidad. La letra se convierte en un ente bidimensional y pasa de ser el reflejo del tipo móvil impreso en el papel a ser una realidad propia y no la representación de otra. Si bien la letra pierde su corporeidad, su abstracción en la pantalla la hace ganar en poder simbólico y constructivo porque su manipulación es más sencilla.

A pesar del gran cambio para la industria de las Artes Gráficas, la nomenclatura de la anatomía del carácter se beneficia de la del tipo móvil y la amplía dotándola de más cualidades humanas.

En la figura tomada del libro de Solomon (p. 89), vemos como la personificación como figura formal se aplica a los vocablos que designan las partes de un carácter. La letra se vivifica a través de su similitud formal con las partes del cuerpo humano. Así, las partes de la letra también tienen ojos, pies, brazos, lóbulos, panzas... En definitiva, tienen cuerpo y vida propia más allá de su función de lingüística de formar palabras. Mediante la Tipografía podemos crear composiciones visuales que duplican su poder significativo como texto y como imagen. Es el caso de los monogramas y caligramas.
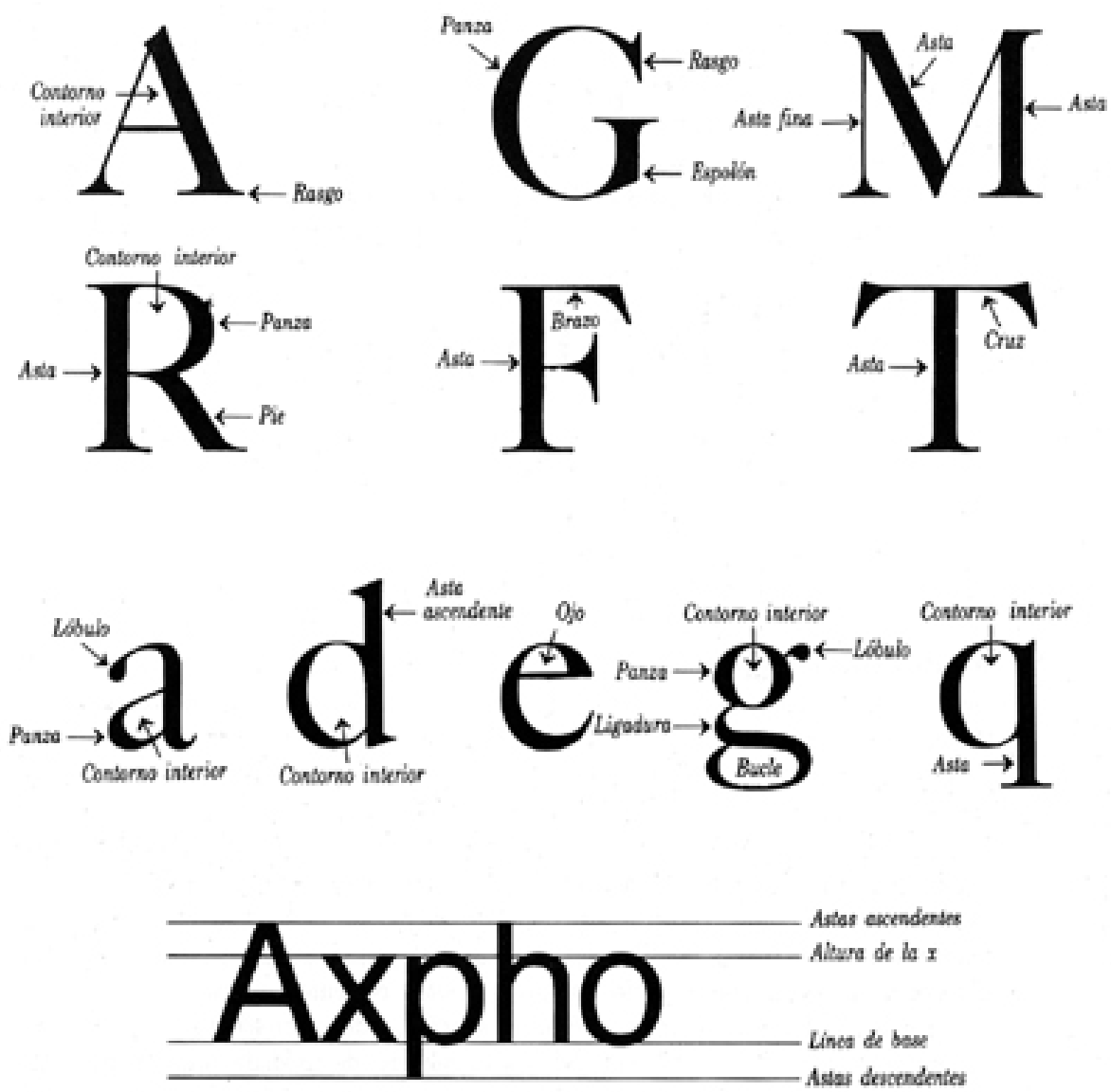
Aunque la letra ha perdido su antigua materia construida a base de la aleación de plomo, antimonio y estaño, en las pantallas de los ordenadores ha ampliado su capacidad vital con su función hipertextual en Internet.

\subsubsection{Lenguaje técnico en Tipografía}

Una parte del lenguaje específico empleado por los tipógrafos lo hemos visto en la anatomía de la letra con el uso de la figura retórica de la prosopopeya. Pero existen muchos términos que bien están tomados de otros campos semánticos, bien han sido acuñados mediante la figura retórica de la metonomia. Con este tropo se sustituye un objeto por otro mediante una relación de causa, procedencia, sucesión, dependencia o posesión. Un ejemplo lingüístico sería la siguiente frase: “Bébete esta copa”. En ella se sustituye el contenido (el líquido) por el continente (la copa).

Trasladado al plano tipográfico, una de las muestras más claras es el vocablo cícero. Este término se empleó por primera vez para designar el tamaño del tipo empleado en 1467 por Sweinheim y Pannartz para imprimir la primera edición de las Epistolae ad familiares de Marco Tulio Cicerón. Podemos apreciar la clara sustitución metonímica del tamaño del tipo de letra (doce puntos) por el autor de la obra. (Martín, E, 1970, p. 142).

Según Rómulo y García, antiguamente, era una práctica habitual nombrar los tamaños de los tipos con el nombre del autor o de la propia obra. Así el cuerpo de letra correspondiente a trece puntos era denominado san agustín porque uno de los libros del santo fue impreso con este cuerpo. También se le denominaba atanasia porque a este tamaño también fue impreso el libro "La Vida de San Atanasio”.

También se usaban vocablos provenientes del campo semántico de lo religioso para designar los tamaños en los que eran impresos textos religiosos: breviario, misal y canon. Otros términos evocaban la pulcritud, delicadeza y cuidado por el detalle de los grabadores de los punzones comparándolo con el trabajo de un joyero: diamante, perla, parisiena, nomparela y miñona.

Como pueden ver en este cuadro completo con las antiguas denominaciones que Rómulo y García han rescatado del “Manual de la Tipografía española, o sea arte de la imprenta”( escrito en 1852 por Antonio Serra y Oliveres), sólo se conserva en la actualidad la nomenclatura del cícero. (Rómulo y García, 2003). 


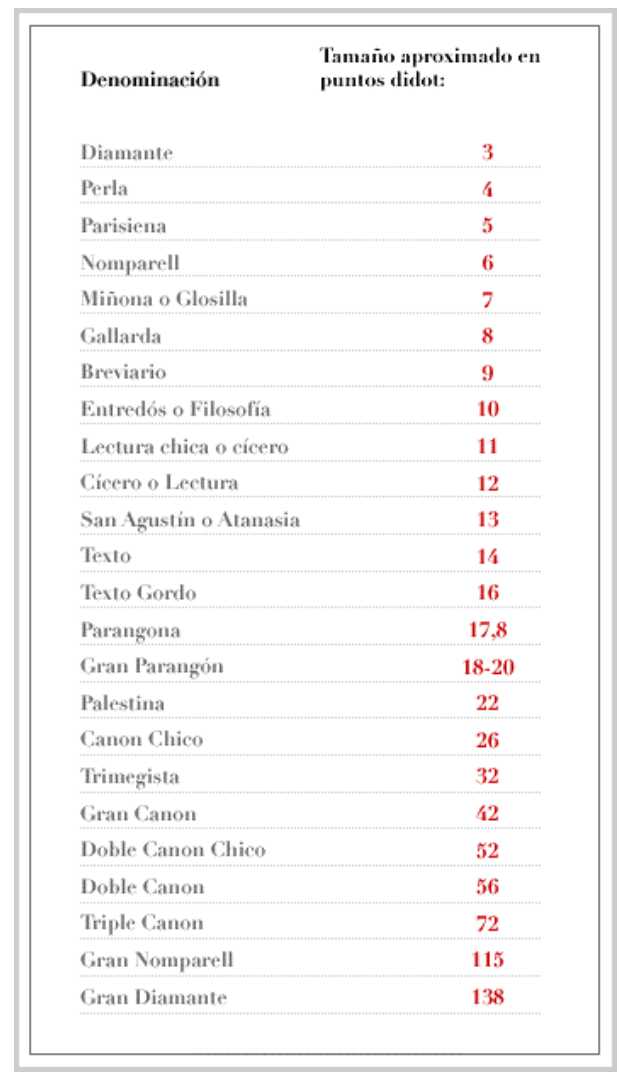

Otra relación metonímica aparecen en los términos de caja alta y caja baja para designar a las mayúsculas y minúsculas, respectivamente. Esta nomenclatura ha sido heredada de los antiguos cajistas de imprenta que tenían clasificados los tipos móviles en un cajón de madera dividido en diversos compartimentos. Las mayúsculas eran colocadas en la parte superior izquierda del cajón y las minúsculas en la parte inferior junto a los números, los signos de puntuación y espacios.

Recuerdo con especial cariño cómo un antiguo responsable de producción de una revista, en la que trabajé hace unos años, me explicaba la diferencia entre las líneas viudas y huérfanas después de propinarme una colleja. La viuda es la última línea de un párrafo que queda colgada al comienzo de una columna y la huérfana la primera línea de un párrafo que queda suelta al final de una columna. Pero él me lo explicaba de una forma más poética y retórica para que lo entendiera de una vez por todas: "la huérfana se queda sola y desamparada al principio de su vida (columna) y la viuda se siente abandonada por la muerte de su marido al final de su vida”.

En este caso se dan dos figuras retóricas a la vez: por un lado, la personificación de la línea, dándole cualidades humanas y, por otro, el símil o comparación entre la situación espacial de una línea dentro de una columna con la situación sentimental de una persona en la vida. 
El tropo del símil también aparece en el término de composición en bandera que designa el párrafo compuesto por diversas líneas de diferente longitud. La forma de este párrafo se asemeja bastante a la de una bandera ondeando al viento.

\subsection{Retórica para construir tipos de letras}

Hasta ahora hemos visto cómo la Retórica actúa sobre la Tipografía en el plano textual para la creación de literatura técnica sobre esta disciplina. Es el turno de abordar la Tipografía y la influencia de la Retórica sobre ella en el plano visual y más concretamente en la creación y diseño de los tipos de letra y sus familias.

Para llegar a esta conclusión, partimos de las operaciones retóricas que el Grupo $\mu$ clasificaron, primero, para la creación de textos en su "Retórica general”, y posteriormente, para la creación de signos plásticos en su “Tratado del signo visual”. Se trata de cuatro sencillas operaciones que nos permitirán partir de un grado cero de lenguaje a un plano superior, lleno de nuevos significados en un lenguaje figurado, ya sea textual o visual:

1. Adjunción: se añaden nuevos elementos que suman significantes y significados nuevos.

2. Supresión: se eliminan unidades, pero no restan significado porque éste permanece implícito en el contexto. El significante desaparece, pero su significado se sobreentiende.

3. Supresión-Adjunción: se quita un elemento para volver a ponerlo en otro sitio.

4. Permutación: se varía el orden de las unidades, pero sin modificar su propia naturaleza.

Las dos primeras operaciones son denominadas sustanciales, porque alteran las sustancia misma de las unidades en las que operan, y las dos últimas son operaciones relacionales que se limitan a modificar las relaciones de posición que existen entre estas unidades. (Grupo $\mu$, 1987, p. 91-95).

Estas mismas operaciones se pueden aplicar en el diseño de tipos de letra, teniendo en cuenta su composición geométrica. Las letras encierran en su espacio las tres formas geométricas fundamentales: el círculo, el cuadrado y el triángulo. Según Antonio e Ivana Tubaro (1994, p. 4647), que citan la obra de Nerdinger “Signo-Escritura + Ornamento”, las tres letras determinantes de un alfabeto son la O, la L y la V. Estos tres caracteres delimitan con su contorno las tres formas geométricas básicas y determinan la forma de las otras letras subdividiéndolas en tres clases:

1. Signos que limitan el espacio con forma de ángulo de giro abierto o cerrado. 
2. Signos que limitan el espacio con forma de ángulo agudo.

3. Signos que limitan el espacio con forma de ángulo recto.

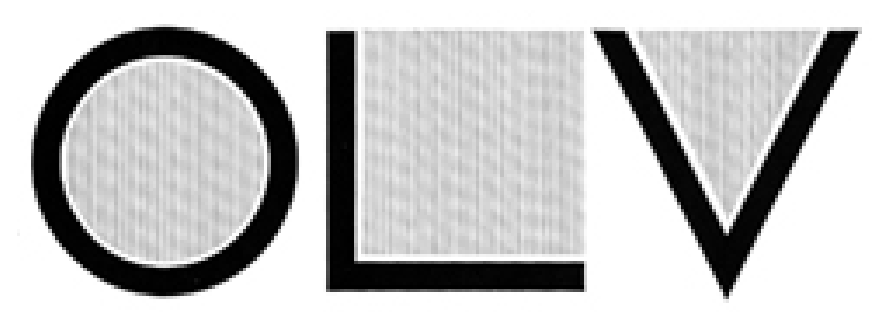

Formas geométricas: círculo, cuadrado y triángulo.

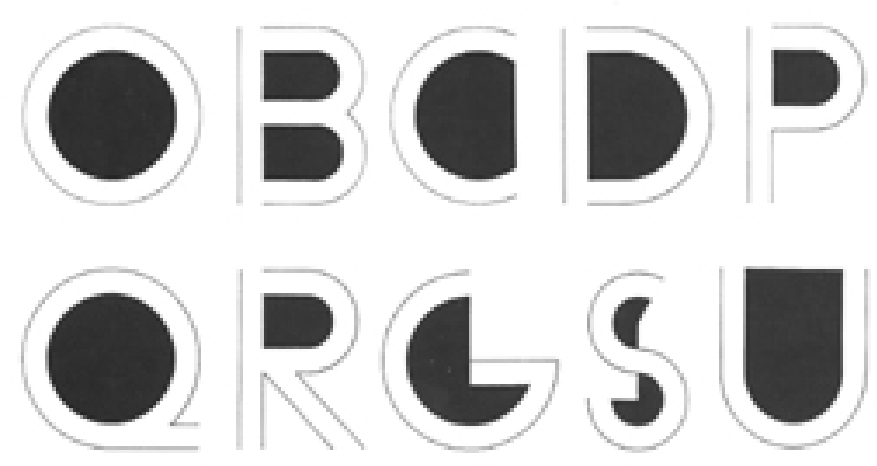

Letras que limitan el espacio con formas en ángulos de giro abierto o cerrado.
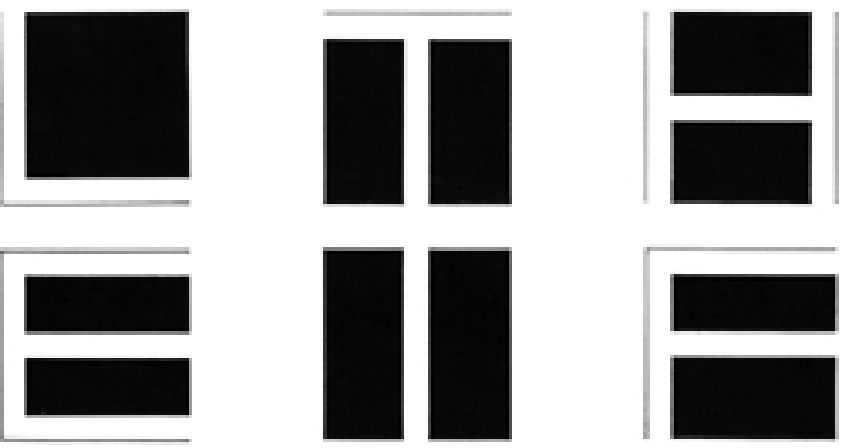

Letras que limitan el espacio con formas en ángulo recto. 

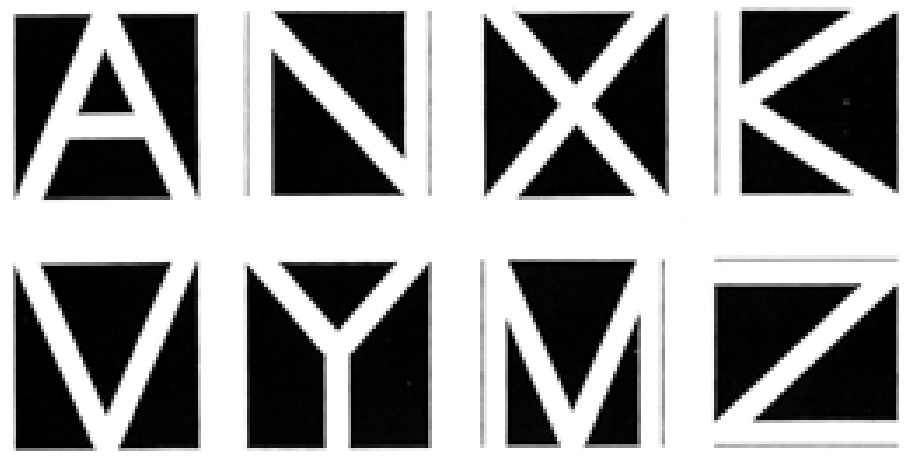

Letras que limitan el espacio con formas en ángulo agudo.

\subsubsection{Líneas fundamentales de la letra}

Estas formas espaciales puede ser simplificadas en cuatro líneas fundamentales: vertical, horizontal, diagonal y curva. A partir de ellas se pueden dibujar todas las letras del alfabeto, como ya adelantó Cristoph Weigel, un diseñador de letras de Nuremberg, en su tratado "El arte de la escritura” de 1716. El autor alemán hizo un profundo estudio morfológico de las letras capitales romanas. Las descompuso en trazos fundamentales y, partiendo éstos, con la adjunción de otros trazos secundarios, elaboró un sistema de pasaje continuo para la reconstrucción de los signos alfabéticos que podemos ver en la siguiente figura (Tubaro,1994, p. 48):

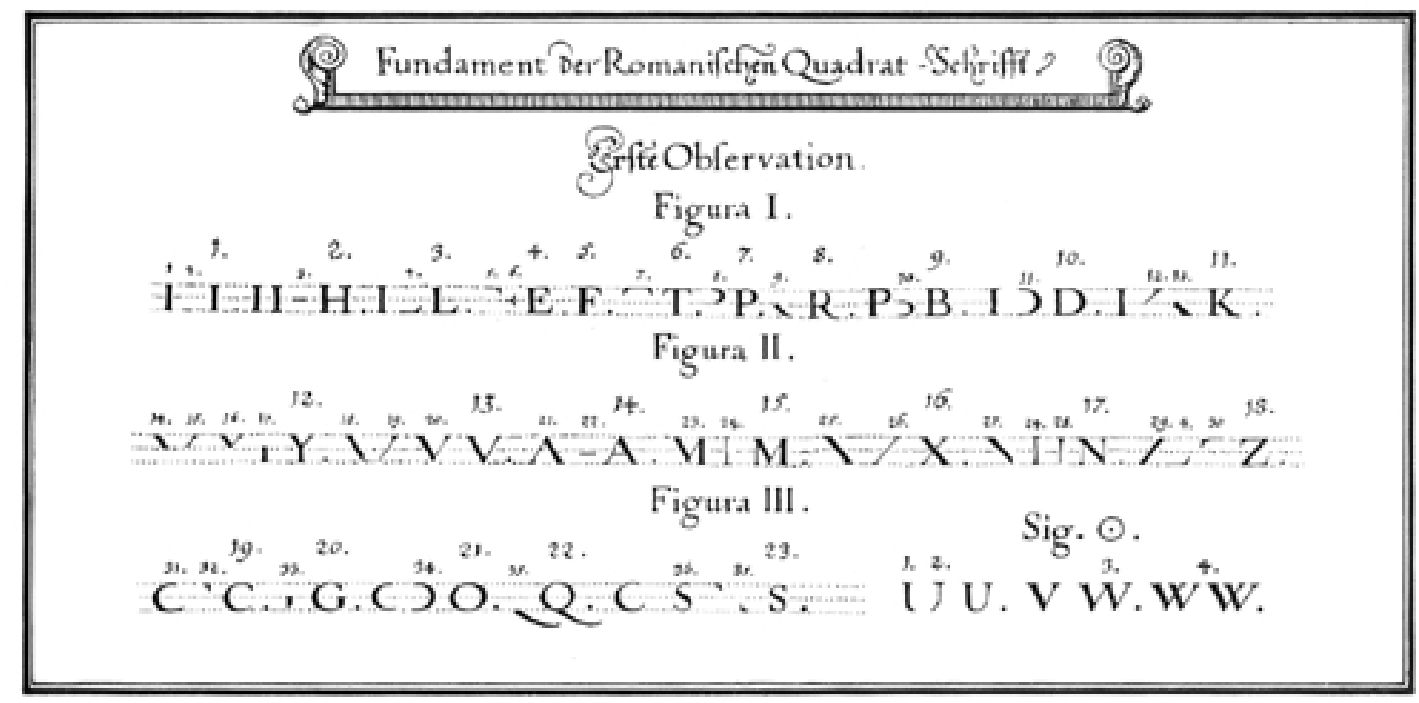

Este sistema de creación de las letras del alfabeto recoge claramente las operaciones retóricas comentadas anteriormente del Grupo $\mu$. Mediante adjunción y/o supresión de líneas fundamentales 
se pueden ir formando letras. Algunas de ellas servirán como modelo para la creación de otras. En la primera parte toma como línea fundamental la vertical, en la segunda, la oblicua y en la tercera, la curva. Utilizando estos trazos como base, se les irán añadiendo trazos secundarios y los remates: De esta forma, parte del trazo vertical para crear la "I”. Mediante la duplicación de esta letra y la adjunción de un trazo horizontal, une los dos trazos verticales creando la “H”... Y así sucesivamente, hasta completar el alfabeto.

Antonio e Ivana Tubaro han adaptado, con ligeras variaciones, el sistema de Weigel para aplicarlo al estudio de un moderno carácter lineal(Tubaro,1994, p. 48-49):

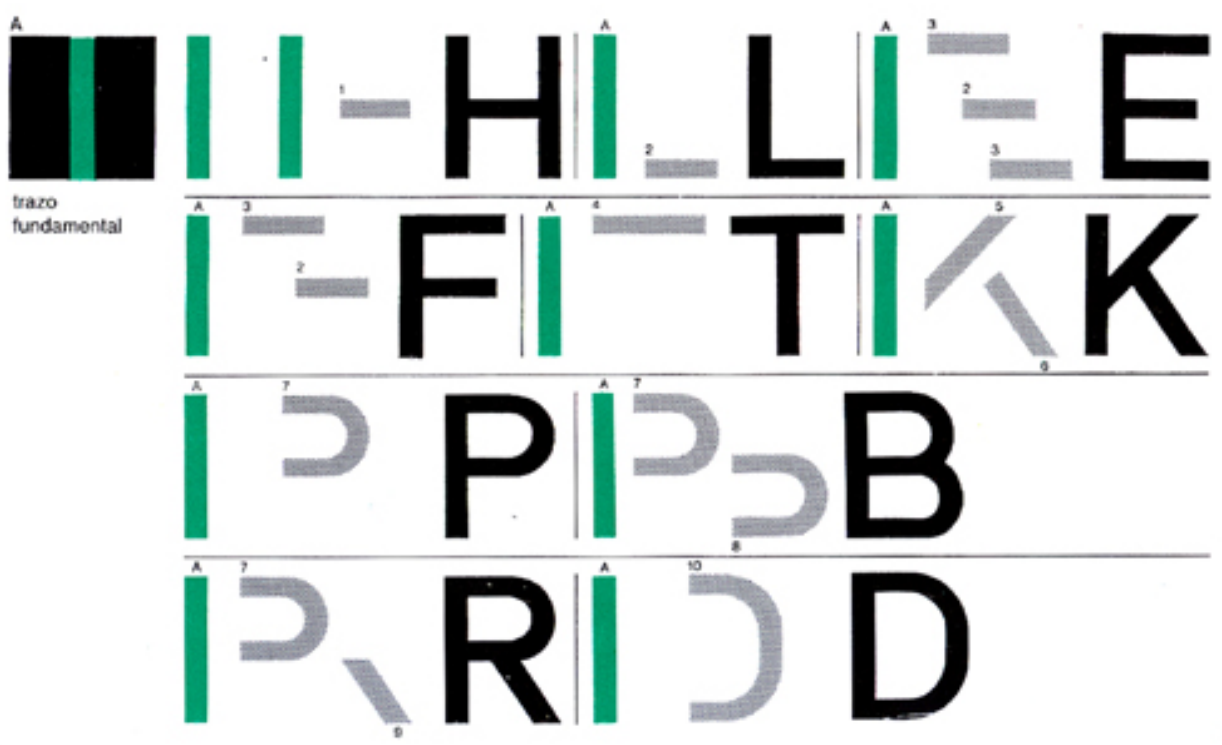

Construcción mediante trazo vertical 

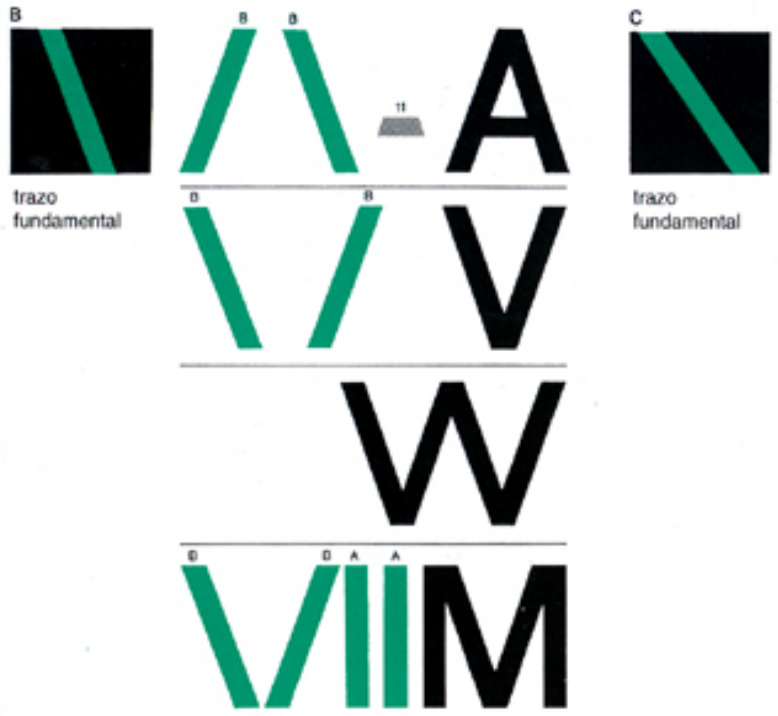
fundamental

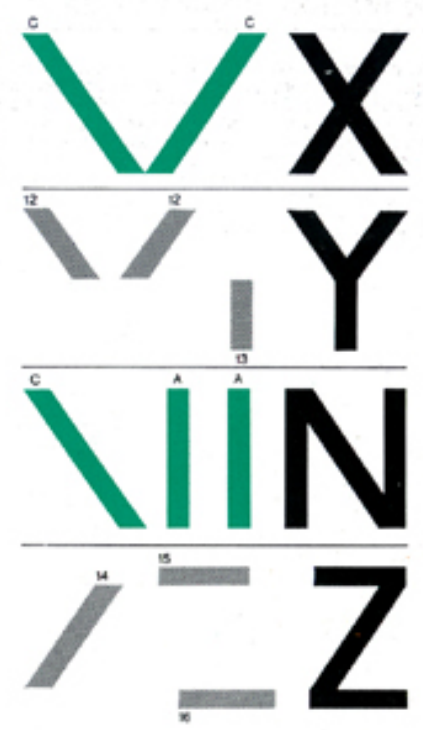

Construcción mediante trazo oblicuo

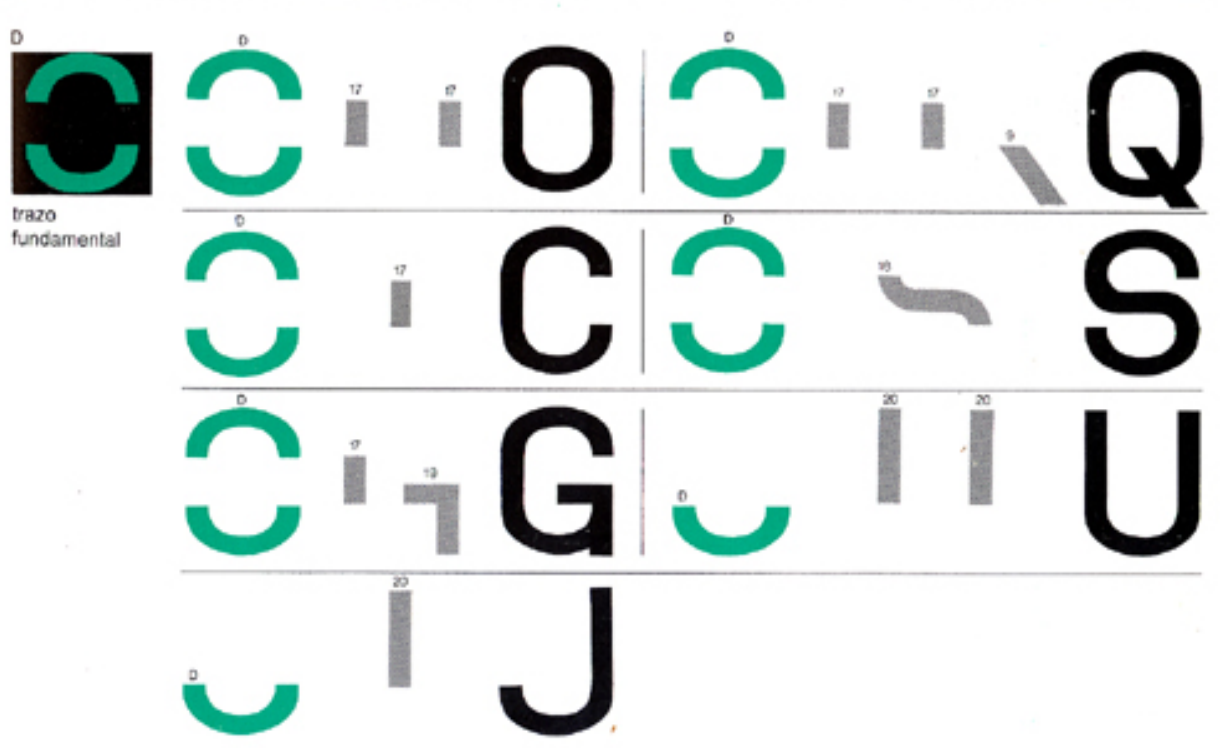

Construcción mediante trazo curvo

Esta modularidad inherente en la geometría de los tipos de letra fue lo que permitió a Joan Trochut Blanchart diseñar un tipo de imprenta llamado el Super-Tipo Veloz que revolucionó las Artes Gráficas españolas en la difícil y estéril época de la postguerra. Se trata de un tipo “integral” basado en módulos con los diferentes trazos fundamentales y juego de remates y florituras que permite crear tipos de letras personalizados, ya sean con o sin serifas. El tipógrafo o cajista, con simples operaciones que nos recuerdan las operaciones retóricas comentadas, adjuntaban, suprimían 
o permutaban las diferentes matrices que constituían la familia del Super-Tipo Veloz para crear numerosos tipos de letra completamente diferentes (Balius, A., 2003).
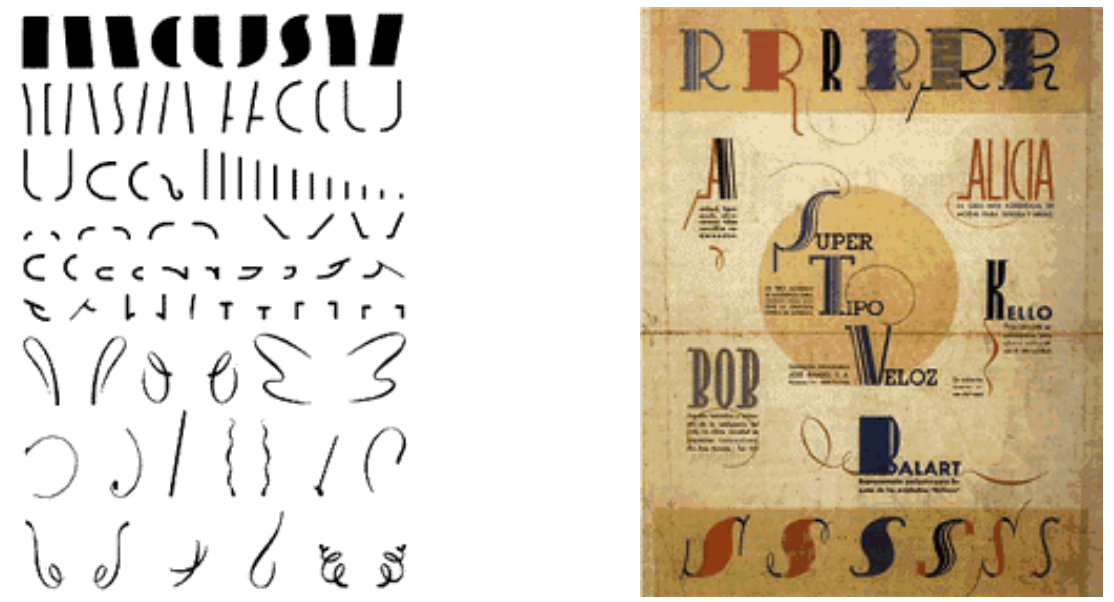

Colección de signos del Super-Tipo Veloz y folleto promocioal de la Fundición Tipográfica Iranzo.

Con este tipo producido en 1942 por la Fundición Tipográfica Iranzo (y que Andreu Balius quiere resucitar para su uso en ordenadores), se cubría las necesidades de los pequeños talleres de imprenta que no podían costearse la compra de diferentes tipos. Consciente de la necesidad de obtener tipos originales y creativos a bajo coste, Trochut creó este sistema tipográfico para la construcción de tipos de letras y alfabetos que sirviera para la composición de textos en pequeños impresos comerciales (tarjetas, anuncios, etiquetas, papelería comercial...) y, a la vez, fuera utilizado como recurso para ilustrar.

Gracias a esta ambivalencia de texto e imagen, con el Super-Tipo Veloz se crearon hermosas piezas de diseño tipográfico con una gran carga retórica: 


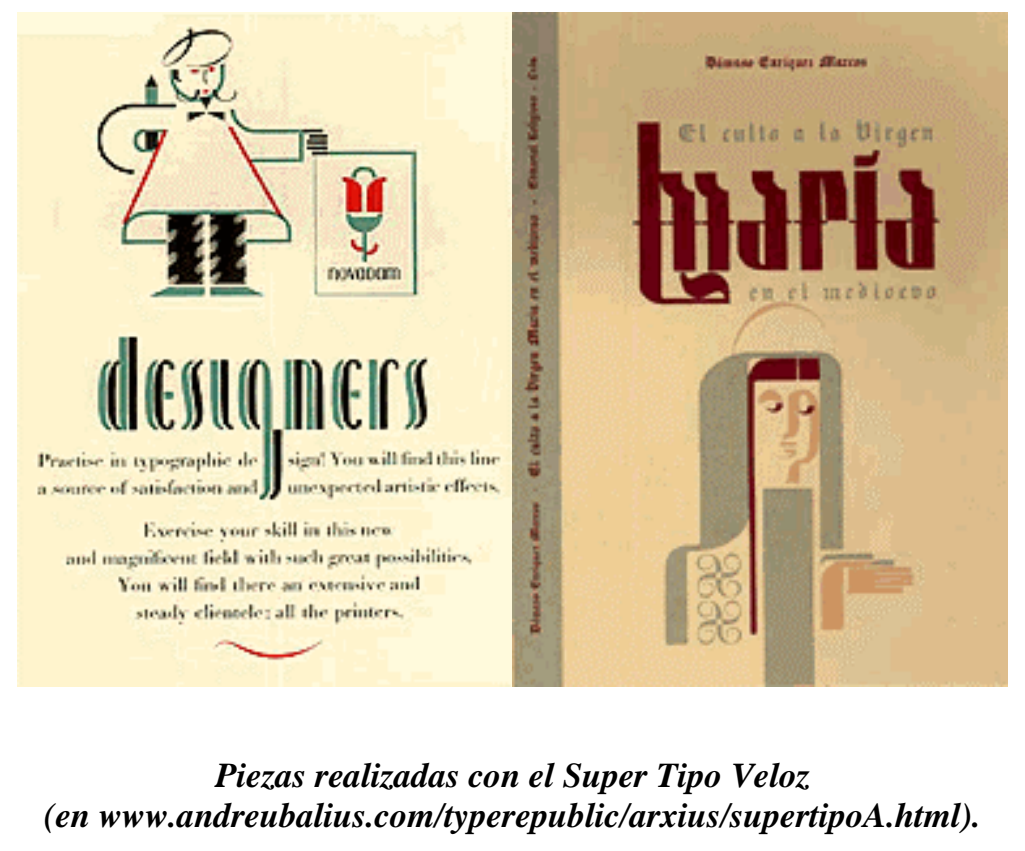

\section{Conclusiones}

- La Retórica ayuda a la Tipografía a explicarse y ser entendida mediante figuras retóricas que hacen más accesibles complicados conceptos a los profanos en la materia. Es frecuente el uso de comparaciones o metáforas para hacer comprensibles ciertos conceptos tipográficos.

- La Retórica crea un lenguaje específico o jerga que usan los expertos en la materia. Estos términos, muchas veces, están tomados de otros campos semánticos ajenos a la Tipografía y adquieren nuevos significados al ser trasladados a un contexto tipográfico. Metáforas, prosopopeyas, metonimias, símiles, etc son figuras retóricas utilizadas en la jerga tipográfica proporcionando nuevas acepciones a vocablos técnicos.

- La Retórica puede ser una excelente herramienta para la construcción de tipos de letras. Éstas, por su composición geométrica, se pueden simplificar en cuatro líneas fundamentales: vertical, horizontal, diagonal y circular. Mediante las operaciones retóricas de adjunción, supresión, sustitución y permutación se pueden crear todas las letras del alfabeto.

- La Retórica también puede ser utilizada como un método creativo aplicado a los diseños tipográficos. Las fases creativas de la elaboración de un discurso clásico (inventio, dispositio y elocutio) se pueden trasladar y aplicar en el proceso creativo del Diseño Gráfico para crear piezas originales, persuasivas y estéticas. 
- La Retórica aporta al diseñador y al tipógrafo los argumentos para que el producto diseñado sea a la vez lógico, coherente, persuasivo, atractivo y estético. De esta forma el peso de la creatividad de la pieza de diseño no reside únicamente en una estética original, sino también en un razonamiento lógico que puede servir al profesional para defender y explicar su trabajo ante el cliente que ha realizado el encargo.

- Bien empleada, la Retórica no busca la artificiosidad y el lenguaje vacuo sino la persuasión, el deleite y la conmoción. Se trata de un sentido de la belleza helénica en la que lo bello es bueno y útil a la vez. Como dijo en una ocasión Rubén Fontana, uno de los máximos exponentes de la tipografía latinoamericana: "Y aunque el Diseño no es arte, en ocasiones, debe permitirse la poesía”.

\section{Bibliografía}

ARISTÓTELES, 1990: Retórica, Gredos, Madrid.

ANIKST, M., 1989, Diseño Gráfico Soviético años 20, Gustavo Gili, Barcelona.

BALIUS, A., 2003, SuperTipo Veloz: Síntomas de la modernidad en http://www.andreubalius.com/typerepublic/arxius/supertipoA.html consultado el 3-3-2005.

FRASCARA, J., 2000: Diseño Gráfico y Comunicación, Ediciones Infinito, Buenos Aires.

GAMONAL ARROYO, R., 2004, David Carson contra Aristóteles: un análisis retórico del Diseño Gráfico en Razón y Palabra nº 37, México, www.razonypalabra.org.mx/anteriores/n37/rgamonal.html consultado el 3-3-2005.

GONZÁLEZ RUÍZ, G., 1994, Estudio de diseño. Sobre la construcción de las ideas y su aplicación a la realidad, Emecé, Buenos Aires.

GRUPO $\mu$, 1993: Tratado del signo visual, Cátedra, Madrid.

GRUPO $\mu$, 1987: Retórica General, Paidós, Barcelona.

JURY, D., 2002: Tipos de fuentes. Regreso a las normas tipográficas, Index Book, Barcelona.

MALDONADO, D., 2001, Diseño \& Comunicación Visual, Ñ Ediciones, Buenos Aires.

MARTÍNEZ DE SOUSA, J., 2001, Diccionario de edición, tipografía y artes gráfica, Trea, Madrid.

MARTÍNEZ-VAL, J., 2002, Tipografía Práctica, Ediciones del Laberinto, Madrid.

McLEAN, R., 1987, Tipografía, Hermann Blume, Madrid.

MORTARA GARAVELLI, B., 1991, Manual de Retórica, Cátedra, Madrid. 
PERELMAN, CH. y OLBRECHTS-TYTECA, L., 1994. Tratado de la Argumentación, Gredos, Madrid.

RÓMULO, I. y GARCÍA, D., 2003, La nomenclatura tradicional de los tipos, en http://www.unostiposduros.com/paginas/histo13.html consultado el 3-3-2005.

RUDER, E., 1983, Manual de Diseño Tipográfico, Gustavo Gili, Barcelona.

SOLOMON, M., 1988, El Arte de la Tipografía, Tellus, Madrid.

SPENCER, H., 1995, Pioneros de la Tipografía moderna, Gustavo Gili, Barcelona.

TUBARO, A. y TUBARO, I., 1994, Tipografía: estudios e investigaciones, Universidad de Palermo, Argentina.

WARDE, B., 1932, “Printing should be invisible”, en McLEAN, R., 1995, Typographers on Type, W.W. Norton \& Company, Londres.

WILLBERG, H.P. y FORSMMAN, F., 2002, Primeros auxilios en Tipografía, Gustavo Gili, Barcelona.

ZIMMERMANN, Y., 1998: Del Diseño, Editorial Gustavo Gili, Barcelona. 